\title{
Selective Targeting of
} 4SO 4 - $\mathrm{N}$-Acetyl-Galactosamine Functionalized Mycobacterium tuberculosis Protein Loaded Chitosan Nanoparticle to Macrophages: Correlation With Activation of Immune System

\section{OPEN ACCESS}

Edited by:

Shahper Nazeer Khan,

Aligarh Muslim University, India

Reviewed by:

Mohammad Sarwar Jamal,

King Abdulaziz University,

Saudi Arabia

Dipesh Dhakal,

Sun Moon University, South Korea

Sandeep Sharma,

Lovely Professional University, India

${ }^{*}$ Correspondence:

Swaleha Zubair

swalehazubair@yahoo.com

Mohammad Owais

mdowais2012@gmail.com

Specialty section:

This article was submitted to

Antimicrobials, Resistance

and Chemotherapy,

a section of the journal

Frontiers in Microbiology

Received: 01 May 2018 Accepted: 26 September 2018 Published: 20 November 2018

Citation:

Mubin N, Umar MS, Zubair S and

Owais M (2018) Selective Targeting of $4 \mathrm{SO}_{4}-\mathrm{N}$-Acetyl-Galactosamine

Functionalized Mycobacterium tuberculosis Protein Loaded Chitosan

Nanoparticle to Macrophages:

Correlation With Activation of Immune

System. Front. Microbiol. 9:2469.

doi: 10.3389/fmicb.2018.02469
Nida Mubin ${ }^{1}$, Mohd. Saad Umar ${ }^{1}$, Swaleha Zubair ${ }^{2 *}$ and Mohammad Owais ${ }^{1 *}$

1 Interdisciplinary Biotechnology Unit, Aligarh Muslim University, Aligarh, India, ${ }^{2}$ Department of Computer Science, Aligarh Muslim University, Aligarh, India

In the present study, we investigated potential of chitosan-based nanoparticles (CNPs) to deliver loaded therapeutic molecules to pathogen harboring macrophages. We fabricated stable CNPs employing ionic cross-linking method and evaluated their potential to target RAW 264.7 cells. The physicochemical characterization of assynthesized CNPs was determined using electron microscopy, infrared microscopy and zeta potential measurement. Next, cellular uptake and intracellular localization studies of CNPs were followed in living RAW264.7 cells using confocal microscopy. We found that both Acr-1 loaded (CNP-A) and 4-SO ${ }_{4}$-GalNAc ligand harboring (CNP-L) chitosan nanoparticle experience increased cellular uptake by Mycobacterium smegmatis infected RAW cells. Following cellular digestion in model macrophage cell line (RAW), CNPs provide an increased immune response. Further, 4-SO 4 -GalNAc bearing CNP-L exhibits high binding affinity as well as antibacterial efficacy toward M. smegmatis. The data of the present study suggest that CNP-based nanoparticle offer a promising delivery strategy to target infected macrophages for prevention and eradication of intracellular pathogens such as $M$. smegmatis.

Keywords: Acr-1 (Rv2031c), M. smegmatis, RAW264.7, 4-SO 4 -GalNAc, CNPs

\section{INTRODUCTION}

Tuberculosis, an important infectious disease, is a leading cause of death across the world. Approximately one-third of the world is infected with Mycobacterium tuberculosis, resulting in more than eight million new cases and two million deaths annually worldwide (Van Soolingen, 2001). Overwhelming numbers of both tuberculosis and non-tuberculous mycobacteria (NTM) have emerged as prevalent clinical entities (Espy et al., 2006). The situation is further complicated by the development of multiple antibiotic resistances among mycobacteria associated infections. Beside emergence of untreatable clinical isolates, failure in the prevention and eradication of mycobacterial biofilm poses a number of serious health issues (Yang et al., 2003). Biofilm formation has been elucidated as an important factor having significant presumption in pathogen virulence. 
Biofilm shields the pathogen from inhibitory effect of both antibiotics as well as immune cells (Hall-Stoodley and Stoodley, 2005). In order to develop effective strategies to curb this important disease, it is desirable to have a better understanding of mycobacterial pathogenesis, involved virulence factors and its interaction with host cell macrophages.

Mycobacterium smegmatis, with its short generation time and requirement of low biosafety level, serves as an appropriate model to study pathogenesis of genus Mycobacterium in general. Further, M. smegmatis shares important virulence gene homology with $M$. tuberculosis therefore might be helpful to understand different host-microbe aspects of virulent Mycobacteria (Altaf et al., 2010). Being relatively long-lived, macrophages are used as a persistent reservoir of invading Mycobacterium spp. (De Chastellier, 2009). Besides offering a safe heaven against antibody onslaught infected macrophages contribute to maintain subtherapeutic concentrations of antibacterial medications through continuous efflux of the antibiotics (Adams et al., 2011). Recently, nanotechnology has emerged as a platform for designing nanoparticles not only as a therapeutic delivery system for controlling mycobacterial infection, however, can be used as adjuvant in development of vaccine or therapeutics carrier for boosting immune response against $M$. tuberculosis infection.

The potential advantage of using nano-formulations over conventional therapies include their capacity to encapsulate or conjugate a variety of drugs/antigens thus offering tunable and site-specific targeted release of the entrapped solute (Weissleder et al., 2005). In addition, nano-system-based delivery system overcome biological barriers improve stability, solubility, bioavailability, and eventually facilitate sustained release of therapeutic substances. A wide range of nanomaterials have been used to deliver M. tuberculosis specific therapeutic agent (Dube et al., 2013). Among various nanoparticle-based delivery systems, chitosan co-polymers have been widely used as effective delivery vehicles (Meerak et al., 2013).

Chitosan-based nanoparticles (CNPs) have been reported to kill target bacterial cells by disturbing their cell wall. The interaction of CNPs with target bacteria ensues in leakage of cytoplasmic contents, inactivation of respiratory enzymes, and protein responsible for RNA and DNA replication. CNPs act like a "molecular knife" and contrive damage to bacterial cell wall even at low concentration (Rabea et al., 2003). The hollow, porous chitosan shell also permits high loading of therapeutics molecule. Additionally, CNPs safeguard degradation of entrapped therapeutics agent by apposing polyvalent layers on the surface of core entrapped material (Amidi et al., 2010). The targeted delivery of the in-house developed CNPs was achieved by conjugation of $4-\mathrm{SO}_{4}-\mathrm{GalNAc}$ on the surface. The ligand $4-\mathrm{SO}_{4}$-GalNAc is recognized by the C-type lectins (pattern-recognition receptor), a highly expressed receptor on the surface of phagocytic macrophages (Drickamer, 1992).

In the present study, we investigated uptake of as-synthesized CNPs by macrophages that eventually evoked host immune response against $M$. smegmatis. We evaluated functionalized CNPs for multipurpose applications. The focus of the study was to establish:

(1) Role of CNPs for its possible antibacterial and anti-biofilm activity against $M$. smegmatis.

(2) Immunological potential of Acr-1 protein loaded chitosan nanoparticles (CNP-A) upon interaction with the host macrophages.

(3) Potential of 4-SO 4 -GalNAc ligand bearing CNPs for their ability to enhance the immunological response against M. smegmatis.

\section{MATERIALS AND METHODS}

\section{Reagent}

Chitosan (70 deacetylation) and $4-\mathrm{SO}_{4}-\mathrm{N}$-acetyl galactosamine (4-SO 4 -GalNAc), Tween 80, tripolyphosphate (TPP) 3-(4,5dimethylthiazol-2-yl)-2,5-diphenyl tetrazolium bromide (MTT), sodium TPP dialysis bag (cut off mol. wt. $=12 \mathrm{kDa}$ ), antibiotic solution (penicillin/streptomycin, $0.1 \% \mathrm{v} / \mathrm{v}$ ) were purchased from Sigma-Aldrich (St. Louis, MO, United States). Tissue culture media Dulbecco's modified Eagle's medium (DMEM) and fetal calf serum (FCS) were purchased from Gibco and plasticwares were purchased from BD Biosciences (United States). Acr-1 was cloned, expressed, and purified following method described elsewhere (Normington et al., 1989). Other reagents and chemicals used were of analytical grade and obtained commercially unless stated otherwise. The triple distilled water was used in all experiments by a three-stage Millipore Milli-Q plus 185 purification system (Bedford, MA, United States).

\section{Cell Line, Animals, and Bacterial Culture Growth Condition}

Mycobacterium smegmatis was cultured in 7H9 broth medium (supplemented with glycerol and tween-80) by shaking for 3 days at $37^{\circ} \mathrm{C}$. Murine macrophage cell line, RAW264.7, was cultured in DMEM (HIMEDIA, Mumbai, India) supplemented with $10 \%$ fetal bovine serum, $1 \%$ penicillin-streptomycin solution, 1\% L-glutamine, and HEPES [4-(2-hydroxyethyl)1-piperazineethanesulfonic acid], at $37^{\circ} \mathrm{C}$ in humidified air supplemented with $5 \% \mathrm{CO}_{2}$.

\section{Synthesis and Characterization of Acr-1 Protein Loaded Chitosan Nanoparticles}

High-molecular-weight chitosan was used in synthesis of CNPs. The nanoparticles were prepared following published method as standardized in our lab (Ko et al., 2002). Briefly, chitosan solution $(1 \mathrm{mg} / \mathrm{ml})$ was prepared in $1 \%$ acetic acid and the mixture was stirred at $37^{\circ} \mathrm{C}$ to obtain a homogeneous solution. Dissolved chitosan solution containing $1 \%$ (w/w) Tween 80 was mixed with $M$. tb Acr-1 protein. Thereafter, $2 \mathrm{ml}$ of an aqueous TPP solution $(1 \mathrm{mg} / \mathrm{ml})$ was added drop wise to the chitosan-Acr-1 solution with stirring. The resulting CNP-A were separated from suspensions by centrifugation for $30 \mathrm{~min}$ at $10,000 \times g$ with successive washes with deionized plain water. The pellet was dried and resuspended in $0.1 \%$ acetic acid solution in normal saline. Plain 
chitosan nanoparticles (CNPs) were prepared following the same method as described above omitting inclusion of Acr-1 protein.

\section{Surface Modification of As-Synthesized CNPs With Ligand 4-SO 4 -GalNAc}

The Acr-1 loaded chitosan NPs was chemically modified with 4$\mathrm{SO}_{4}$-GalNAc employing method as reported earlier with slight modifications (Alex et al., 2011). In brief, 4-SO 4 -GalNAc was dissolved in $0.1 \mathrm{M}$ acetate buffer ( $\mathrm{pH}$ 3.0) and added to assynthesized Acr-1 loaded chitosan suspension (CNP-A). The mixture was agitated at ambient temperature $\left(30 \pm 2^{\circ} \mathrm{C}\right)$ for $48 \mathrm{~h}$ to accomplish the reaction. The as-formed particles (CNP-L) were dialyzed against triple distilled water in dialysis bag (cut off mol. wt. $=12 \mathrm{kDa}$ ) for $18 \mathrm{~h}$. Finally, an aliquot of nanoparticle (CNP-L) suspension was centrifuged for $30 \mathrm{~min}$ at $10,000 \times g$ and $4^{\circ} \mathrm{C}$. The pellet was re-suspended in $100 \mu \mathrm{l}$ of normal saline. The average particle size, polydispersity index (PDI), and zeta potential of the CNPs, CNP-A, and CNP-L nanoparticles was determined employing a Zeta-sizer 3000 (Malvern Instruments Ltd., Malvern, United Kingdom) in 5 mM HEPES (pH-7.4). The formulation was dispersed in low concentration phosphate buffer (5mM $\left.\mathrm{PO}_{4}, \mathrm{pH}-7.4\right)$ for determination of zeta potential. The particle size distribution of the NPs was reported as a polydispersity index.

\section{Fourier Transforms Infrared Spectroscopy}

Fourier transforms infrared spectroscopy (FTIR) was used to characterize as-synthesized CNPs, employing method published elsewhere (Kong and $\mathrm{Yu}, 2007$ ). The chemical conjugation of 4$\mathrm{SO}_{4}$-GalNAc with chitosan was confirmed by FTIR spectrum, recorded on FTIR multi-scope spectrophotometer equipped with spectrum v3.02 software.

\section{High-Resolution Transmission Electron Microscopy (HR-TEM)}

The as-synthesized CNPs were subjected to morphological characterization; employing high-resolution transmission electron microscopy (HR-TEM; Hashimoto et al., 2004). A drop of various formulations of CNPs was placed onto a carbon-coated copper grid, forming a thin liquid film. For TEM analysis, a drop of aqueous suspension containing the CNP, CNP-A, and CNP-L-based NPs was put on carbon-coated copper grids to get a thin liquid film. The samples were dried and desiccated before loading onto a specimen holder.

\section{Percent Entrapment Efficiency (\%EE)}

For determination of actual amount of Acr-1 protein in formed CNPs, an aliquot of CNP-A $(1 \mathrm{ml})$ was suspended in mixture of dimethyl sulfoxide (DMSO) and $0.1 \%$ acetic acid (1:20) and vortexed for half an hour followed by overnight magnetic agitation in the dark at $37^{\circ} \mathrm{C}$; centrifuged at $10,000 \times g$ for $15 \mathrm{~min}$. Complete solubilization of NPs caused release of entrapped Acr1 in the surrounding solution. At various time intervals, the supernatant was decanted and released Acr-1 was determined employing micro BCA protein assay method (Agnihotri et al., 2004). A sample consisting of plain CNPs re-suspended in PBS was used as blank. The experimental set up was performed at least in triplicate. The amount of protein entrapped in the formed NP was determined following. Loading efficiency (LE) for Acr-1 was determined calculated as follows:

$$
\mathrm{LE}=\frac{\text { Total amount of Acr-1 }- \text { free Acr-1 }}{\text { Total amount of Acr-1 }} \times 100 \%(\mathrm{w} / \mathrm{w})
$$

\section{In vitro Killing Assay to Determine Anti-mycobacterial Potential of As-Synthesized CNPs}

To determine the anti-mycobacterial activity of various asformed NPs, viz., CNP, CNP-A, and CNP-L, the NPs were coincubated with $M$. smegmatis $\left(4 \times 10^{5}\right.$ bacteria per well) in 7H9 broth medium in a 96-well plate. The optical density of the bacteria was adjusted to 1.0 at $600 \mathrm{~nm}$. The total volume of the incubation mixture was kept $200 \mu \mathrm{l}$ per well. Bacteria were harvested at the indicated time points and the number of colony-forming units (CFUs) present in aliquoted sample was determined. The experiment was performed in triplicate and values were averaged from three independent trials.

\section{Anti-mycobacterial Potential of As-Synthesized CNPs as Determined by Agar Diffusion Assay}

Mycobacterium smegmatis culture was grown for $48 \mathrm{~h}$ in $7 \mathrm{H} 9$ medium and pelleted at $5000 \times g$ for $5 \mathrm{~min}$. The final pellet was washed with $1 \times$ PBS and re-suspended in 7H9 medium. The suspended culture $(100 \mu \mathrm{L})$ was spread uniformly on $7 \mathrm{H} 9$ agar plates and incubated at $37^{\circ} \mathrm{C}$ for $30 \mathrm{~min}$. Increasing amount of CNP, CNP-A, and CNP-L were loaded onto various wells along with control drug. The zone of inhibition was determined by measuring clear zone in bacterial lawn around corresponding well after 24-48 h of incubation (Bonev et al., 2008).

\section{Cytotoxicity Assay}

RAW264.7 cells $\left(1 \times 10^{5}\right.$ cells $\left./ \mathrm{ml}\right)$ were grown in DMEM in a 96well plate at $37^{\circ} \mathrm{C}$ in an atmosphere of $5 \%$ carbon dioxide $\left(\mathrm{CO}_{2}\right)$ for $24 \mathrm{~h}$. The cells were exposed to increasing concentration of various NP for $24 \mathrm{~h}$. To determine the cell viability after $24 \mathrm{~h}$ exposure to various formulation, viz., CNP, CNP-A, and CNP-L, $20 \mu \mathrm{L}$ of MTT stock solution $(5.0 \mathrm{mg} / \mathrm{ml}$ in PBS, $\mathrm{pH}$ 7.4) was dispensed in each well. The plate was incubated for $4 \mathrm{~h}$ at $37^{\circ} \mathrm{C}$ in an atmosphere of $5 \% \mathrm{CO}_{2}$ in the dark. The supernatant was aspirated carefully, and blue formazan crystals formed by the reduction of MTT were dissolved in buffer (sodium dodecyl sulfate [SDS] [11 g] in $0.02 \mathrm{M}$ hydrochloric acid $[\mathrm{HCl}][50 \mathrm{ml}]$ and isopropanol $[50 \mathrm{ml}])$. The absorbance was measured at $570 \mathrm{~nm}$ on a micro plate reader (Bio-Rad Model 550, United States). The experiment was performed in triplicate and mean value was used as the final representative result. Since absorbance is proportional to the number of living cells, cell viability was represented by the absorbance ratio of exposed cells 
to untreated control cells, which was expressed as a percentage. Chitosan-untreated cells in media were used as control (Fisichella et al., 2009).

\section{FITC Labeling of Nanoparticle and M. smegmatis Cell}

Various as-synthesized chitosan NPs were labeled with fluorescein isothiocyanate (FITC) following procedure as published elsewhere (Lu et al., 2007). Briefly, CNP-based formulation $(500 \mathrm{mg}$ ) was incubated with FITC ( $5 \mathrm{mg}$, dissolved at $2.5 \mathrm{mg} / \mathrm{ml}$ in DMSO) in $50 \mathrm{ml}$ sodium carbonate buffer $(0.1 \mathrm{M}$, $\mathrm{pH}$ 9.2) overnight at $37^{\circ} \mathrm{C}$ in the dark. Unreacted FITC was quenched by treatment with Tris buffer $(10 \mathrm{ml}, 1.0 \mathrm{M}, \mathrm{pH} 8.3)$ for $30 \mathrm{~min}$. The labeled nanoparticles were extensively washed with sterile water until no color; residue remained followed by dehydration with absolute ethanol and acetone, and finally dried under vacuum in the dark at room temperature.

Mycobacterium smegmatis was labeled with TRITC following published protocol (Chassaing et al., 2011). Briefly, bacterial cells were suspended in $1 \times$ PBS. TRITC $(2.5 \mathrm{mg} / \mathrm{ml}$ in DMSO $)$ was added to the bacterial cell suspension and stirred at room temperature in the dark for 3-4 h. Subsequently, Tris buffer $(2.0 \mathrm{ml}, 1.0 \mathrm{M}, \mathrm{pH} 8.3)$ was added, and reaction mixture was stirred for additional $15 \mathrm{~min}$ at room temperature to quench the free form of fluorescent labeling reagent. The labeled bacteria were centrifuged at $7000 \times g$ and dialyzed against water followed by lyophilization in dark.

\section{Cellular Uptake Study of As-Formed CNPs by RAW264.7 Cells Employing Confocal Laser Microscopy}

The interaction of as-synthesized CNPs with RAW264.7 cells was followed by cellular uptake study employing confocal laser microscopy. Briefly RAW cells, seeded at a density of $5 \times 10^{5}$ cells/cover slip using DMEM along with $10 \%$ FBS, were cultured at $37^{\circ} \mathrm{C}$ in a humidified atmosphere with $5 \% \mathrm{CO}_{2}$. Various FITC-labeled CNPs, denoted as FITCCNP, FITC-CNP-A, and FITC-CNP-L, were incubated with macrophage cells at $37^{\circ} \mathrm{C}$. Uptake kinetics of as-synthesized nanoparticle by RAW264.7 cells was assessed in time-dependent manner (Wang et al., 2012). The cells were rinsed three times with $1 \times$ PBS and fixed with $4 \%$ paraformaldehyde. For the nucleus staining, fixed cells were incubated with $1.0 \mathrm{mg} / \mathrm{ml} \mathrm{DAPI}$ solution at $37^{\circ} \mathrm{C}$ for $30 \mathrm{~min}$, prior to analyzing confocal microscopy. All the samples were examined under confocal laser scanning microscopy (LSM510 DUO, Zeiss).

\section{Antibacterial Potential of As-Synthesized CNPs Against Intracellular M. smegmatis}

To examine antibacterial potential of as-synthesized CNPs against intracellular $M$. smegmatis, infected macrophages $\left(5 \times 10^{5}\right.$ RAW cells) were treated with as-synthesized CNPs for $24 \mathrm{~h}$. The RAW cells were exposed to M. smegmatis infection for $3 \mathrm{~h}$ prior to treatment. Control setups consisting of uninfected RAW264.7 were also exposed to as-synthesized
CNPs. Extracellular bacteria were killed by the addition of gentamicin $(20 \mu \mathrm{g} / \mathrm{ml})$. After stipulated incubation, cells were washed and lysed with $0.5 \%$ Triton X-100; intracellular survival was estimated by plating serially diluted cultures on $7 \mathrm{H} 9$ agar plates and the colonies were enumerated after $72 \mathrm{~h}$.

\section{Potential of As-Synthesized CNPs to Generate Intracellular ROS}

Chitosan-based nanoparticles mediated generation of intracellular ROS in treated bacterial cells was estimated using 2',7' dichlorofluorescein diacetate (DCFDA) dye (Eruslanov and Kusmartsev, 2010). M. smegmatis cells $\left(1 \times 10^{5}\right.$ cells $/$ well $)$ were seeded on coverslips. After $24 \mathrm{~h}$, the bacterial cells were exposed to CNPs for $6 \mathrm{~h}$. The un-interacted CNPs were washed off using $1 \times$ PBS. Thereafter, the cultured cells were exposed to DCFDA dye $(30 \mu \mathrm{M} / \mathrm{ml})$ for $30 \mathrm{~min}$ at $37^{\circ} \mathrm{C}$. The excess of DCFDA was removed following subsequent washing. The CNP treated experimental and control cells were visualized for qualitative analysis of ROS generation, employing fluorescence microscope (Zeiss model, United States).

\section{Anti-biofilm Potential of As-Synthesized CNPs}

Mycobacterium smegmatis biofilm was cultured in polystyrene 96-well microtiter plates (Corning Inc., United States) following published procedure (Stepanoviæ, 2000). Briefly, overnight cultured $M$. smegmatis cells were suspended at the 1.0 absorbance (O.D.600) in RPMI-1640 medium. After 3 days preformed biofilm was treated with $100 \mu \mathrm{g}$ of the nanoparticle suspension $/ 50 \mu \mathrm{L} /$ well using 96 -well microtiter plates. The plates were covered with lids and incubated at $37^{\circ} \mathrm{C}$. After $36 \mathrm{~h}$ of treatment with CNPs, the plate was washed with PBS, and the biofilm activity was assessed by XTT [2,3-Bis-(2-methoxy-4nitro-5-sulfophenyl)-2H-tetrazolium-5-carboxanilide] reduction assays. Biofilms were also observed by scanning electron microscopy (SEM) and confocal microscopy. The biofilmharboring wells were washed with PBS buffer, fixed with glutaraldehyde, dehydrated with ethanol, and dried in vacuum desiccators. The samples were coated with gold and observed by a scanning electron microscope. The M. smegmatis biofilms for confocal microscopic studies were prepared employing similar methods, except that medium $7 \mathrm{H} 9$ also was used for culture.

\section{Live/Dead Staining of CNPs Treated M. smegmatis Biofilm}

To study the effect of CNPs on biofilm inhibition, M. smegmatis was grown to an $\mathrm{OD}_{600}$ of 1.0 and diluted 1:100 in $7 \mathrm{H} 9$ broth medium. Aliquots of $600 \mu \mathrm{l}\left(10^{7} \mathrm{CFU} / \mathrm{ml}\right)$ of diluted culture were transferred to a sterile $13 \mathrm{~mm}$ coverslip. The cells were exposed to MIC and sub-MIC concentration of CNPs. Control samples were prepared on a sterile glass coverslip with $M$. smegmatis cells only (positive) and 7H9 media only (negative) without any CNPs. The wells were washed twice with $3 \mathrm{~m}$ of sterile $0.9 \%$ saline. 
The cells were stained with a $1.5 \mathrm{ml}$ mixture of $0.8 \mu \mathrm{M}$ SYTO9 green fluorescent dye and $10 \mu \mathrm{M}$ propidium iodide (PI) red fluorescent dye of Live/Dead staining kit (LIVE/DEAD BacLight Bacterial Viability Kit, Thermo Fisher Scientific, Waltham, MA, United States; Boulos et al., 1999).

\section{Effect of CNPs on M. smegmatis Biofilm as Revealed by Confocal Microscopy}

Confocal microscopy was employed to assess effect of assynthesized CNPs on M. smegmatis biofilm. The biofilm was grown on a cover slip. After $72 \mathrm{~h}$, the preformed biofilms were treated with a sub inhibitory concentration of various CNPs. The treated biofilm was visualized by confocal microscopy using layer-scanning model. The treated M. smegmatis biofilm was washed with PBS, fixed with $4 \%$ formaldehyde, and stained for SYTO-9/PI staining for $1 \mathrm{~h}$ followed by washing step to remove unbound biofilm and dye, observed with a confocal microscope (LSM710, Zeiss, Germany).

\section{Effect of As-Synthesized CNPs on Expression of Co-stimulatory Molecules in Treated Macrophages}

To study the role of various as-synthesized CNPs on expression of co-stimulatory molecule, $5 \times 10^{5}$ macrophages cells in DMEM (supplemented with 10\% FCS, and 2\% HEPES) were seeded in each well of a 24-well plate. Bacteria were grown to an $\mathrm{OD}_{600}$ ranging from 0.6 to 0.8 , passed through a 26-gauge needle three times and allowed to settle for $10 \mathrm{~min}$. The infection was carried out at a multiplicity of infection (MOI) of 10:1 for $3 \mathrm{~h}$ in duplicate wells. The extracellular bacteria were removed by three washes using PBS. The cells were incubated in DMEM medium supplemented with $100 \mu \mathrm{g} / \mathrm{ml}$ gentamycin for $1 \mathrm{~h}$ and treated with various CNPs formulation. After $24 \mathrm{~h}$ of nanoparticle treatment at $37^{\circ} \mathrm{C}$ and $5 \% \mathrm{CO}_{2}$, cells were recovered and stained with phycoerythrin-labeled fluorescent antibodies obtained from BD Pharmingen. Cell surface expression of CD80, CD86, CD40, and major histocompatibility complex (MHC) class II was assessed by flow cytometer (EPICS XL; Beckman Coulter; Dong et al., 1999).

\section{Statistical Analysis}

Statistically significance of data among groups was determined using the Student's $t$-test (two-tailed, equal variances).

\section{RESULTS}

\section{Characterization of Surface Decorated CNPs Employing FTIR and TEM}

We employed chitosan and TPP as the "fixing materials" to fabricate chitosan shells through anionic and cationic electrostatic interactions. Tween 80 was used to prevent particle aggregation. TPP was used as the cross-linkers to form the CNPs particles. The resultant CNP-A did not allow leakage of entrapped Acr-1 protein. The TEM analysis suggests that the mean particle size of the CNPs in $5 \mathrm{mM}$ saline was 17 and $29 \mathrm{~nm}$ for CNP-A and CNP-L nanoparticles as compared with $14 \mathrm{~nm}$ for unloaded CNPs (Figure 1A). The polydispersity index was 105 for plain CNP, 186 for CNP-A, and 226 for CNP-L, respectively. The PDI data indicated a narrow size distribution and a good colloidal stability of the as-synthesized NPs. The as-synthesized CNPs acquired positive surface charge. A significant increase in zeta potential was observed, when CNPs were conjugated with Acr-1 and ligand. CNP-A and CNP-L had a zeta potential of \pm 11.2 and $12.2 \mathrm{mV}$ in $5 \mathrm{mM}$ saline compared with \pm 9.01 for plain CNP. Next we assessed the zeta potential of macrophage co-cultured with CNPs. We observed highest zeta potential in CNP-L group $( \pm 30.2)$ as compared to both CNP-A $( \pm 26.3)$ and CNP ( \pm 24.5$)$ group. The control macrophages (untreated) had a negative zeta potential value $(-13.3 \mathrm{mV}$; Supplementary Figure S1).

\section{FTIR Spectroscopy}

The FTIR spectroscopic studies of various as-synthesized CNPs have been shown in Figure 1B. The FTIR spectra of prepared chitosan and its conjugated form consist of various important absorption bands characteristics of various functional groups. The spectrum was recorded in the middle infrared wave number in 4000 to $500-1 \mathrm{~cm}^{-1}$ range. The amine $\mathrm{NH}$ - stretching vibrations were observed at $3500-3300 \mathrm{~cm}^{-1}$ and that for $\mathrm{C}-\mathrm{H}$ were observed at 2900 in various CNPs groups. The absorption peaks at $1600-1000 \mathrm{~cm}^{-1}$ can be correlated to the presence of the $\mathrm{C}=\mathrm{O}$ stretching of the amide $\mathrm{I}$ band. Bending vibrations of the $\mathrm{N}-\mathrm{H}$ ( $\mathrm{N}$-acetylated residues, amide II band), $\mathrm{C}-\mathrm{H}$ bending, $\mathrm{OH}-1$ bending, respectively, were also observed in all three CNPs group. An upshifted new peak appeared at high wave number in both CNP-A and CNP-L between 1690 and 1630 and can be attributed to the amide $\mathrm{C}==0$ stretch of Acr protein. The strong sharp peak in $3400-2900 \mathrm{~cm}^{-1}$ was also observed in upshifted manner re-presenting amine NH stretch in both CNPA and CNP-L. The observed broadening of peak at $3400 \mathrm{~cm}^{-1}$ in CNP-A and CNP-L can be correlated to hydrogen bonding. The spectrum showed the characteristic peaks of the substituted secondary amide in the $3300-3400 \mathrm{~cm}^{-1}$ region. The peaks observed at 1100 to $600 \mathrm{~cm}^{-1}$ can be attributed to the C-S stretching vibrations of sulfides and disulfides bonds in CNP-L (Figure 1B).

\section{Encapsulation Efficiency of CNP-A Nanoparticles}

Earlier reports suggested that the encapsulation efficiency of antigen with nanoparticle was due to the electrostatic and hydrophobic interaction between the Acr-1 protein and CNP and this could be a reason for the increase in size of the particle (Gan and Wang, 2007). Figure 1 represents the TEM images of the CNP-A nanoparticle that showed some structural changes when loaded with Acr-1 (Figure 1A). The entrapment efficiency of the Acr-1 in CNP was calculated and it was found that $79 \%$ of Acr1 antigen was loaded in CNP. On the other hand when Acr-1 loaded chitosan (CNP-A) was conjugated with ligand, increase in size was observed in CNP-L (Figure 1A) 


\section{A}
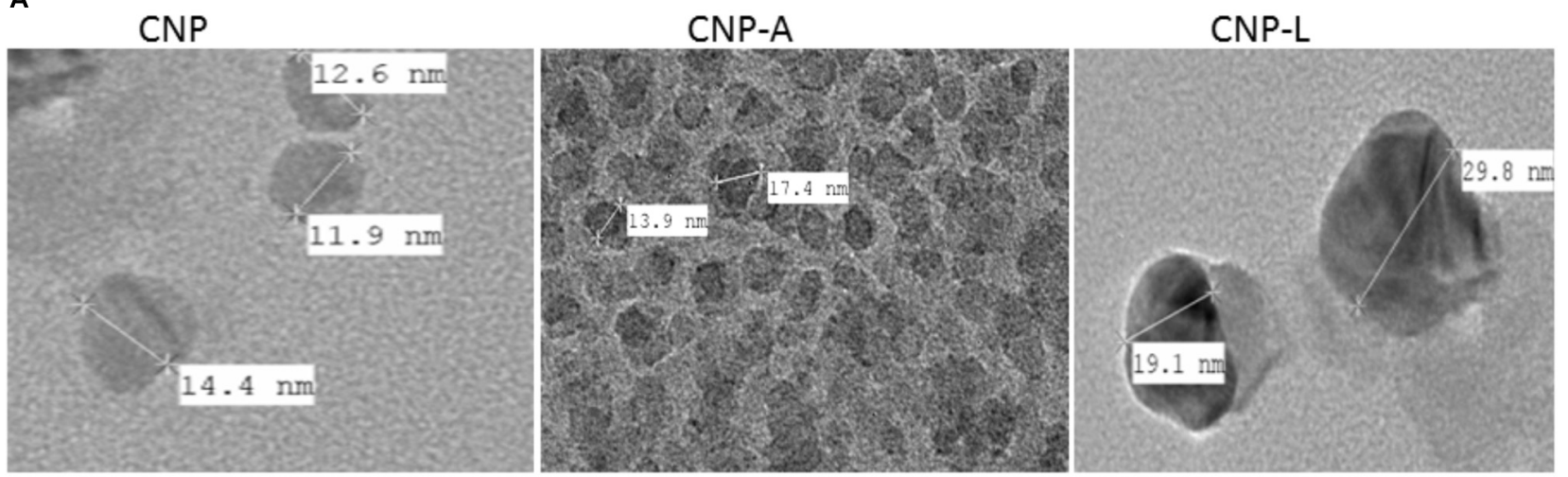

B

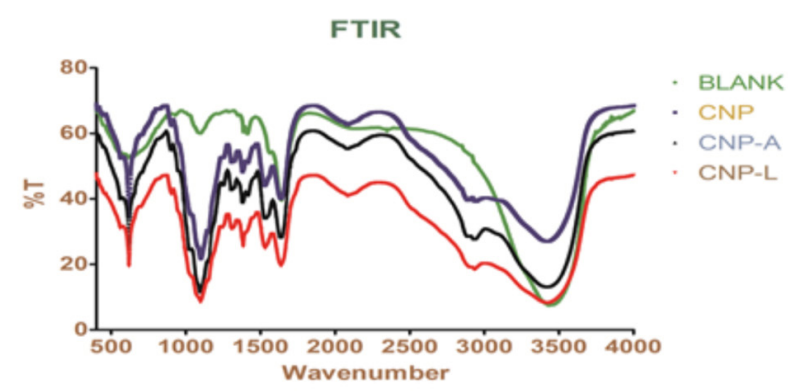

C

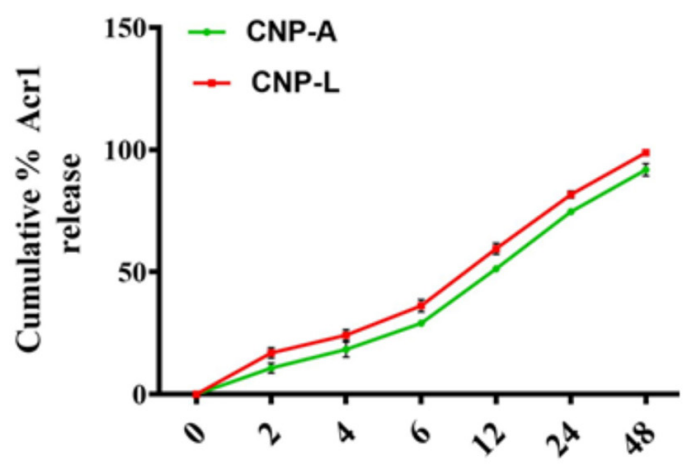

Time(h)

FIGURE 1 | (A) Physical characterization of as-synthesized CNPs. Transmission electron microscopic images of CNP, CNP-A, and CNP-L (CNPs) nanoparticles (scale bar; $100 \mathrm{~nm}$ ). (B) Fourier transformation infrared microscopy of CNPs (polydispersion index and zeta potential of CNPs as determined by Malvern Zeta Sizer). (C) Acr-1 antigen release from CNP-A/CNP-L nanoparticle at stipulated pH-5.5.

\section{In vitro Antigen Release}

The profile of Acr-1 antigen release, under simulated acidic ( $\mathrm{pH}$ 5.5) environment, from CNP-A loaded and CNP-L nanoparticles are shown in Figure 1C. The amounts of the antigen released from the CNPs after $6 \mathrm{~h}$ of incubation at $\mathrm{pH} 5.5$ exceed $35 \%$ of the loaded protein. The particle showed good physical stability in acidic condition and their size did not noticeably change. The present result showed that under simulated phagosomal condition ( $\mathrm{pH}-5.5) 70 \%$ of the loaded antigen was released after 12-14 h from CNP-A and CNP-L nanoparticle.

\section{Antibacterial Activity of Various As-Synthesized CNPs}

The antibacterial activity of various as-synthesized CNPs against M. smegmatis was assessed following published protocol (No et al., 2002). Exponentially grown bacteria were incubated with increasing concentrations of various CNPs. The MIC of various CNPs was determined using serial twofold dilution against bacterial inoculum of $1 \times 10^{8} \mathrm{CFU} / \mathrm{ml}$. The positive control consisted of $7 \mathrm{H} 9$ broth medium with tested bacterial inoculum and negative control contained only broth. The
MIC is the minimal concentration of antimicrobial agent that visually inhibits $99 \%$ growth of bacteria. The MIC was assessed on the basis of visual turbidity of the tubes both before and after incubation of as-synthesized CNPs. The residual bacterial load was assessed by harvesting bacteria at various time points and plating serial dilutions of suspension on 7H9 agar plates. The residual live bacteria were enumerated after $72 \mathrm{~h}$ incubation. The $\mathrm{MBC}$ was observed to ensure presence or absence of bacterial growth in $7 \mathrm{H} 9$ agar plates. The MBC endpoint is defined as the lowest concentration of antimicrobial agent that kills $99.9 \%$ of the initial bacterial population (Supplementary Figure S2). CNP-A formulation showed less antibacterial activity as compared to plain CNP and CNP-L in significant manner (Figure 2A) The observation suggests that Acr-1 inhibits antibacterial activity. Both CNP and CNP-L nanoparticles treatment showed significant inhibitory activity against $M$. smegmatis in dose-dependent manner (Figure 2B). The anti-mycobactericidal activity of various assynthesized CNPs was also assessed by Agar diffusion method. All synthesized CNPs were evaluated for their antibacterial activity against $10^{6} \mathrm{CFU} / \mathrm{ml}$ of the $M$. smegmatis on agar plate. After $72 \mathrm{~h}$, all three NPs, viz., CNP, CNP-A, and CNP-L 


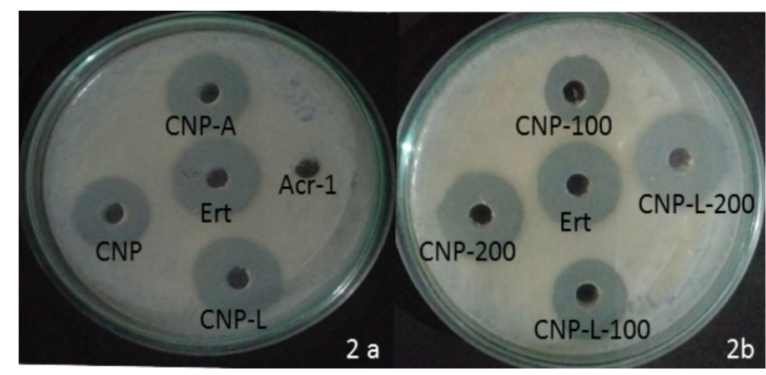

FIGURE 2 | Dose-dependent killing of $M$. smegmatis by various as-synthesized CNPs. (A) Antibacterial activity of various CNPs-based formulation was assessed by agar diffusion method: various CNPS (CNP, CNP-A, and CNP-L) were loaded at $100 \mu \mathrm{g} / 20 \mu \mathrm{L}$ dose into wells of the plate exposed to $M$. smegmatis. Growth inhibition was determined by measuring the zone of inhibition formed in bacterial lawn after $48 \mathrm{~h}$; erythromycin was used as a control. (B) M. smegmatis culture was incubated with increasing concentrations of both CNP and CNP-L group to study dose-dependent killing efficiency of as-synthesized CNPs.

showed a clear zone of inhibition. The plate loaded CNP-A group demonstrated less zone of inhibition as compared to CNP and CNP-L formulation. Acr-1 protein alone failed to impart any antibacterial activity, as suggested by a dense population of bacteria in agar plate. Interestingly, CNP-A contribute important role in immuno-stimulation of the host by evoking immune response against $M$. smegmatis (Figure 8).

\section{CNPs Mediated Damage of M. smegmatis Cell Wall}

Scanning electron microscopy was used to study interactions between CNPs and M. smegmatis (Figure 3A) shows that M. smegmatis cells lost it cellular integrity after exposure to CNP and CNP-L treatment at a concentration of $100 \mu \mathrm{g} / \mathrm{ml}$ whereas untreated cells (control group) remained intact (Je and Kim, 2006). Longer treatment with CNPs resulted in the formation of large sized bacterial aggregates. Next we assessed the potential of pre-formed CNP and CNP-L nanoparticles to inhibit pre formed M. smegmatis biofilm under in vitro conditions by monitoring SEM analysis. We observed that both CNP groups were efficient to inhibit biofilm mass after $36 \mathrm{~h}$ treatment. CNP-L treatment was more effective as compared to CNP at the same dose in terms of biofilm inhibition (Figure 3B).

\section{Intracellular ROS Production by As-Synthesized CNPs}

In order to determine intracellular ROS production by CNPs, we followed fluorescence probe DCFH-DA employing fluorescence microscope. DCFDA is cell permeant indicator and employed to probe ROS. The acetate groups of the DCFH-DA are removed by intracellular esterases to form a non-fluorescent product 2',7' dichlorofluorescein (DCFH). The DCFH dye reacts with generated reactive oxygen species (ROS) to produce the fluorescent product 2,7 dichlorofluorescein (DCF) which gets trapped within the cells making it fluorescent.
A significant quantitative concentration-dependent increase in $\%$ ROS was observed increase in the form of fluorescence on treatment with as-synthesized CNPs at $100 \mu \mathrm{g} / \mathrm{ml}$ (Figure 4).

\section{Assessment of Biofilm Inhibition by As-Synthesized CNPs Using SYTO-9 Dye}

Biofilms limit diffusion of drug molecules and proffer to the pathogenesis of underlying infection. The biofilm inhibition is crucial to halt bacterial colonization and also to increase the susceptibility of bacteria against given therapeutic agent. M. smegmatis is known for its ability to form biofilms (Zambrano and Kolter, 2005). We determined potential of CNPs to inhibits biofilm formation (and/or disrupted the preformed biofilms) under in vitro conditions by monitoring the binding of the SYTO-9 dye to live bacterial cells (SYTO9 Stained cell - green color). As Acr-1 protein did not impart any antimicrobial activity, we avoid including CNP-A group in biofilm treatment studies. To assess the effect of CNP treatment on disruption of preformed biofilms, M. smegmatis biofilms were grown for $48 \mathrm{~h}$ in a six-well microtiter plate. The biofilm was exposed to increasing concentration of CNPs. Significant, disruption of preformed biofilms was observed in CNP and CNP-L nanoparticle treated group (killed bacteria were stained with PI-Red stain; Figure 5). In contrast, early exposure of $M$. smegmatis to CNP and CNP-L NPs resulted in significant inhibition of biofilm formation. Our confocal data showed that both CNP and CNP-L at dose of $100 \mu \mathrm{g} / \mathrm{ml}$ treatment for $36 \mathrm{~h}$ decreased more than 50 and $60 \%$ of the biofilms inhibition, respectively. Whereas exposure with both CNP and CNP-L at the dose $200 \mu \mathrm{g} / \mathrm{ml}$, dose resulted in more than 60 and $65 \%$ killing of bacteria, respectively (Figure 3C).

\section{Safety Evaluation and Cytotoxicity Assay}

Despite potent antibacterial activity of chitosan, the use of CNP as therapeutic agents is limited. It can be speculated that chitosan conjugation with ligand $\left(4-\mathrm{SO}_{4}\right.$-GalNAc) coating resulted in modulation of host immune cell component. As $M$. smegmatis is an intracellular pathogen, we used the MTT assay to test the cytotoxicity of various CNPs in a dose-dependent manner on RAW264.7 cell line (Kuo et al., 2005). In MTT assay, metabolically active cells reduce MTT to purple formazan; the intensity of dye read at $570 \mathrm{~nm}$ is directly proportional to the number of viable cells. The cytotoxicity assay showed a dose-dependent drop in cell viability (Figure 6). The cell viability was not significantly affected at $24 \mathrm{~h}$ of incubation in the presence of $100-200 \mu \mathrm{g} / \mathrm{ml} \mathrm{a}$ dose that was found to be lethal for the bacteria tested in this study. Cell viability dropped drastically at the dose of $500 \mu \mathrm{g} / \mathrm{ml}$. We also examined the macrophages cell morphology in a monolayer culture after the treatment with varying concentrations of CNP, CNP-A, and CNP-L NPs. Microscopic observations showed no distinct morphological changes in the cells treated with a bactericidal dose $(200 \mu \mathrm{g} / \mathrm{ml})$ of CNPs group. 

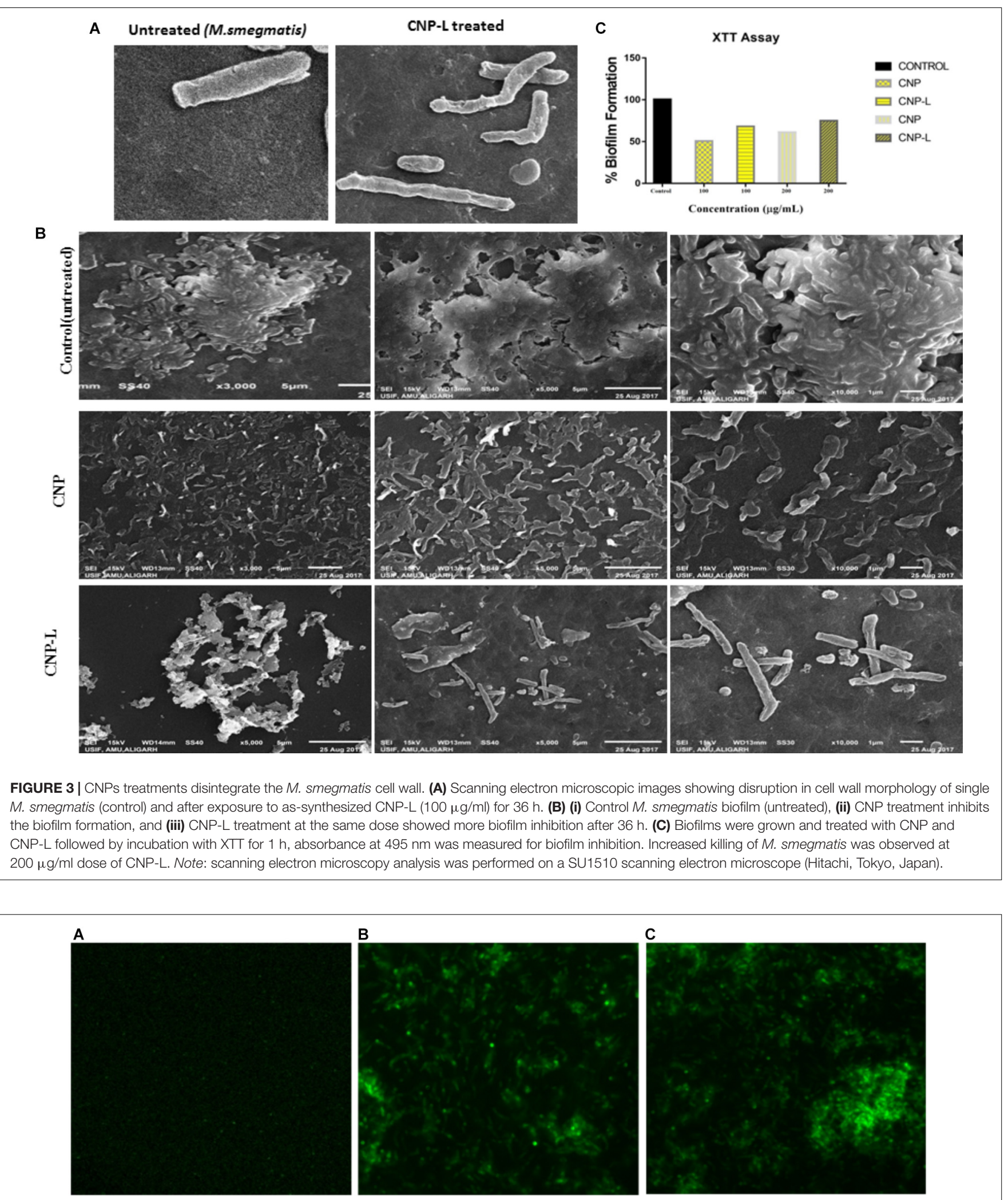

FIGURE 4 | Fluorescence micrograph showing the generation of intracellular reactive oxygen species (ROS) using DCFDA dye in CNPs treated M. smegmatis cells (A). Control $(\mathbf{B}, \mathbf{C})$ cells exposed to CNP and CNP-L at prefix MIC dose for $6 \mathrm{~h}$ showing increases in fluorescence intensity demonstrating excess generation of ROS production. 


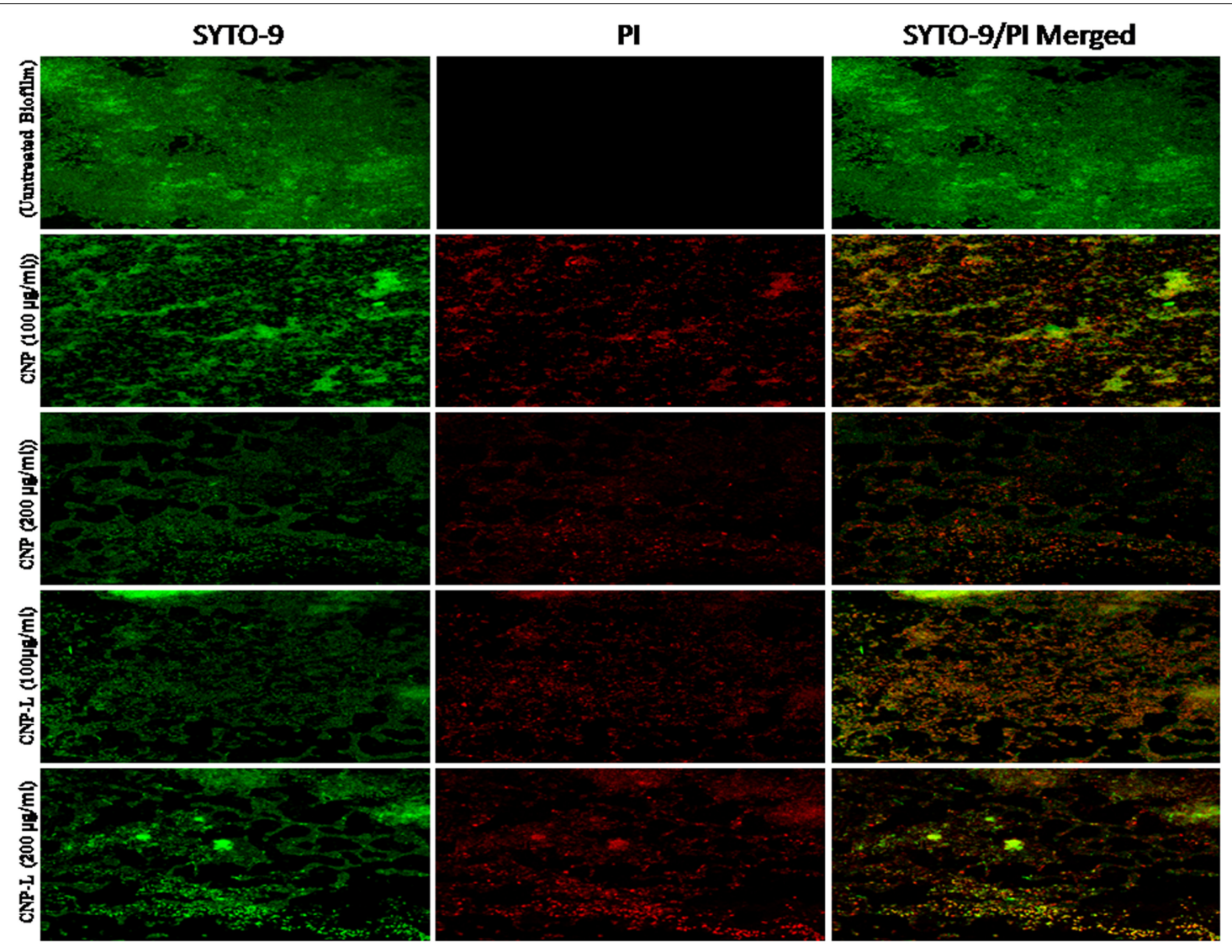

FIGURE 5 | Confocal microscope image showing $M$. smegmatis biofilm inhibition by CNPs as visualized in 63X oil immersion magnification: anti-biofilm activity of CNPs was assessed by incubating $M$. smegmatis with increasing concentrations of CNPs for $36 \mathrm{~h}$ in a six-well plate. The treated biofilm was stained with SYTO-9/PI. The addition of increasing concentration (100-200 $\mu \mathrm{g} / \mathrm{ml})$ of CNPs inhibited M. smegmatis biofilm formation. Red-dye showing PI-stain corresponds to killing activity, and Green dye showing viable bacteria in pre formed biofilm. Yellow color corresponds to co-localization of merged green and red dye at same place.

\section{Cellular Uptake of CNPs by RAW264.7 Cell}

We followed interaction of CNPs with macrophages in context of surface charge (zeta potential) of the target cells. Our goal was to determine cellular binding of nanoparticle with macrophage membrane. All cells generate an electrical potential across their plasma membrane driven by concentration gradient of charged ions. NPs used in diagnostic and therapeutic applications are treated as inert probes or delivery vehicles for infectious diseases. While NP-delivered therapeutic agent expected to alter a cell, it is assumed that the NP itself will not change the biological system as such. Previous reports had shown that the cellular binding of NPs is affected by membrane potential (He et al., 2010). We first examined the membrane potential of RAW264.7 cells in order to study the effect of binding propensity of CNPs to the plasma membrane independent of internalization. Membrane potential of intact macrophages cell was checked followed by CNPs internalization. Cellular binding of CNPs with macrophages cell showed increased positive potential.

Next, we employed confocal microscopy study to investigate the interaction of NPs with RAW cells. RAW264.7 cells were treated with varying concentration of FITC-labeled CNP, CNP-A, and CNP-L for $4 \mathrm{~h}$ (Figure 7A; He et al., 2010). Confocal microscopy images demonstrated that FITC-CNP-A and FITCCNP-L NPs are efficiently taken up by infected macrophages as compared to plain CNP group. The uptake of CNP-A and CNP-L by RAW264.7 cells was at least five times more to that of plain CNPs. The data highlighted representative images of live cells incubated with FITC-CNP, CNP-A, and CNP-L for $4 \mathrm{~h}$ in RAW264.7 control cells and TRITC-tagged M. smegmatis infected macrophages cell. While in untreated control cultures (Figure 7A), low fluorescence was detected. Infected cells treated with FITC-CNP-L NPs, fluorescence intensity increased with the NPs uptake (Figure 7B). The lowest fluorescence intensity was observed in control CNP group tested, high level of cellular uptake was observed in CNP-L group, at the same dose. The results support the data and demonstrate that the FITC-CNP-L conjugated NPs were efficiently and rapidly taken up by the infected cells demonstrating the role of galactose residue ligand for specific recognition by C-type lectins, mannose receptor highly expressed on infected macrophages. In addition, the confocal analysis allowed us to visualize the intracellular distribution of the fluorescent Acr-1 (either encapsulated in chitosan alone and along with surface modified galactosylated 


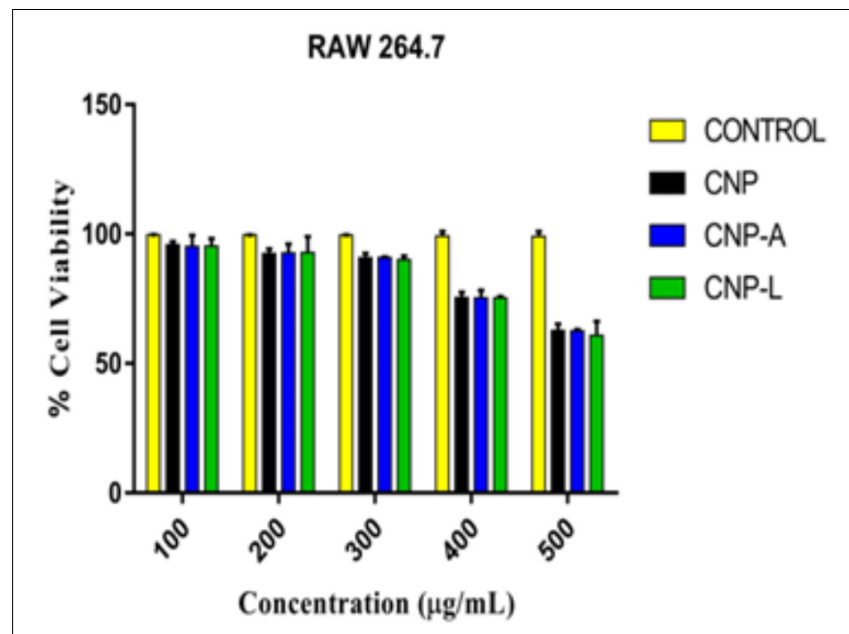

FIGURE 6 | Assessment of cytotoxic activity of various as-synthesized CNPs against mouse macrophages 264.7 cells. Macrophages were treated with increasing concentration of CNPs for $24 \mathrm{~h}$ : cell viability was determined by MTT assay. Experiments were performed in triplicate; results are shown as mean \pm SD.

$\mathrm{CNP}$ ) into the macrophage cells. Figure $7 \mathbf{B}$ shows that the fluorescence is distributed inside the cells, confirming the internalization of the NP in infected cell. By comparing the cellular uptake of CNP, CNP-A, and CNP-L, the uptake of CNP-L (Figures 7A,B) in both uninfected control cells and infected cells, we again observed a higher rate of delivery of FITC-CNP-L NPs confirming the targeted delivery of therapeutic molecule through ligand targeted mannose receptor in infected macrophage cells.

\section{Efficacy of CNPs in Killing of Intracellular M. smegmatis and Also Upregulation in Expression of Co-stimulatory Molecules in Infected Macrophages After Treatment With CNPs}

Macrophages are professional phagocytic cells that can internalize particles up to $10 \mu \mathrm{m}$ in size. Keeping this fact into consideration, we hypothesized that exogenous addition of CNPs groups may lead to endocytosis of all modified nanoparticles by macrophages, resulting in intracellular killing of bacteria. Fluorescence microscopy was used to follow internalization of FITC-labeled CNPs by TRITC-M. smegmatis infected macrophages. CNP internalization was followed in both infected as well as uninfected macrophages under identical conditions. The control macrophages (uninfected) showed minimal FITC-CNPs internalization; however, the TRITCM. smegmatis infected macrophages showed active endocytosis of fluorescently labeled CNP-L NPs as compared to CNP and CNP-A NPs group (Figure 7B).

The infection conditions and intracellular survival kinetics of $M$. smegmatis had already been well characterized in macrophages (Anes et al., 2006). For this reason, we chose this model to evaluate the killing activity of $M$. smegmatisinfected macrophages after $24 \mathrm{~h}$ treatment with various CNPs.
Macrophages were infected with $M$. smegmatis infection, before $3 \mathrm{~h}$ prior to interaction with various CNPs at prefixed dose. The concentration of nanoparticles used in the study was found to be non-toxic to the macrophages (Figure 6). A significant reduction in intracellular bacterial survival was observed after $24 \mathrm{~h}$ treatment with CNP-L and CNP-A in terms of CFU count after plating on $7 \mathrm{H} 9$ agar as compared with untreated macrophages (Figure 8). Treatment with CNPs had no effect on the phagocytosis of $M$. smegmatis by RAW cells.

Next, we checked how Acr-1-based nanoparticles can enhance immune response against $M$. smegmatis infection. The infected macrophages undergo subtle changes upon establishment of M. smegmatis infection. The optimum expression of both $\mathrm{MHC}$ as well as co-stimulatory molecules on APCs is imperative in deciding its future interaction with effector $\mathrm{T}$ cells in terms of their activation (Demotz et al., 1990). Many reports suggest adjuvant potential of CNPs against infectious diseases (Prego et al., 2010). The confocal data demonstrated that uninfected macrophages are less efficient in CNP intake while infected macrophages are more efficient in uptake of CNP-L. Further, the flow cytometer data showed that both CNP-A and CNP-L nanoparticles successfully upregulate expression of CD80/86/40/MHC-II molecule on RAW264.7 cells (Figure 9).

\section{DISCUSSION}

Mycobacterium pathogens adapt intracellular mode of parasitism as a strategy to counteract antibody onslaught. Incidentally intracellular abode also help them to withstand antibiotics used as a modality in tuberculosis treatment, as they fail to access bacteria residing inside the cells (Wakamoto et al., 2013). The situation needs development of drug delivery system that can deliver effective antibiotic directly inside the infected cells (Wu et al., 2005). In recent times, nanomedicines have received a great deal of attention as a therapeutic agent because of their unique mode of action (Moghimi et al., 2005). The data of the present study suggest that a specific dose of CNPs can inhibit or kill the mycobacterium without harming the host cells. We prepared CNPs and assess their anti-mycobacterial activity. It was found that plain CNPs possess strong antibacterial activity, which depends on a multiple factors, viz., chitosan molecular weight; the viscosity, ionic strength, $\mathrm{pH}$, and presence of metallic ions in the medium; the temperature; and the concentration of chitosan in composite preparations (Rinaudo et al., 1993).

Next, we supplemented CNPs with Acr-1 protein and evaluated the antibacterial as well as immunomodulatory role of the combination. We also surface decorated CNP-A with a ligand (4-SO $\mathrm{S}_{4}$-GalNAc) that recognized C-type lectins, surface molecule of macrophages or other APC (McGreal et al., 2005). Various assynthesized CNPs used in this study were found to be stable at both physiological as well as at $4^{\circ} \mathrm{C}$ up to at least for 1 month time period even when present in solution.

Under specific conditions, chitosan provided a hollow cage like structure that protects Acr-1 and also coerce a strong interaction with ligand on the periphery of nanocomposites ( $\mathrm{Li}$ et al., 2008). Chitosan binds to metal ions of ligand because of 


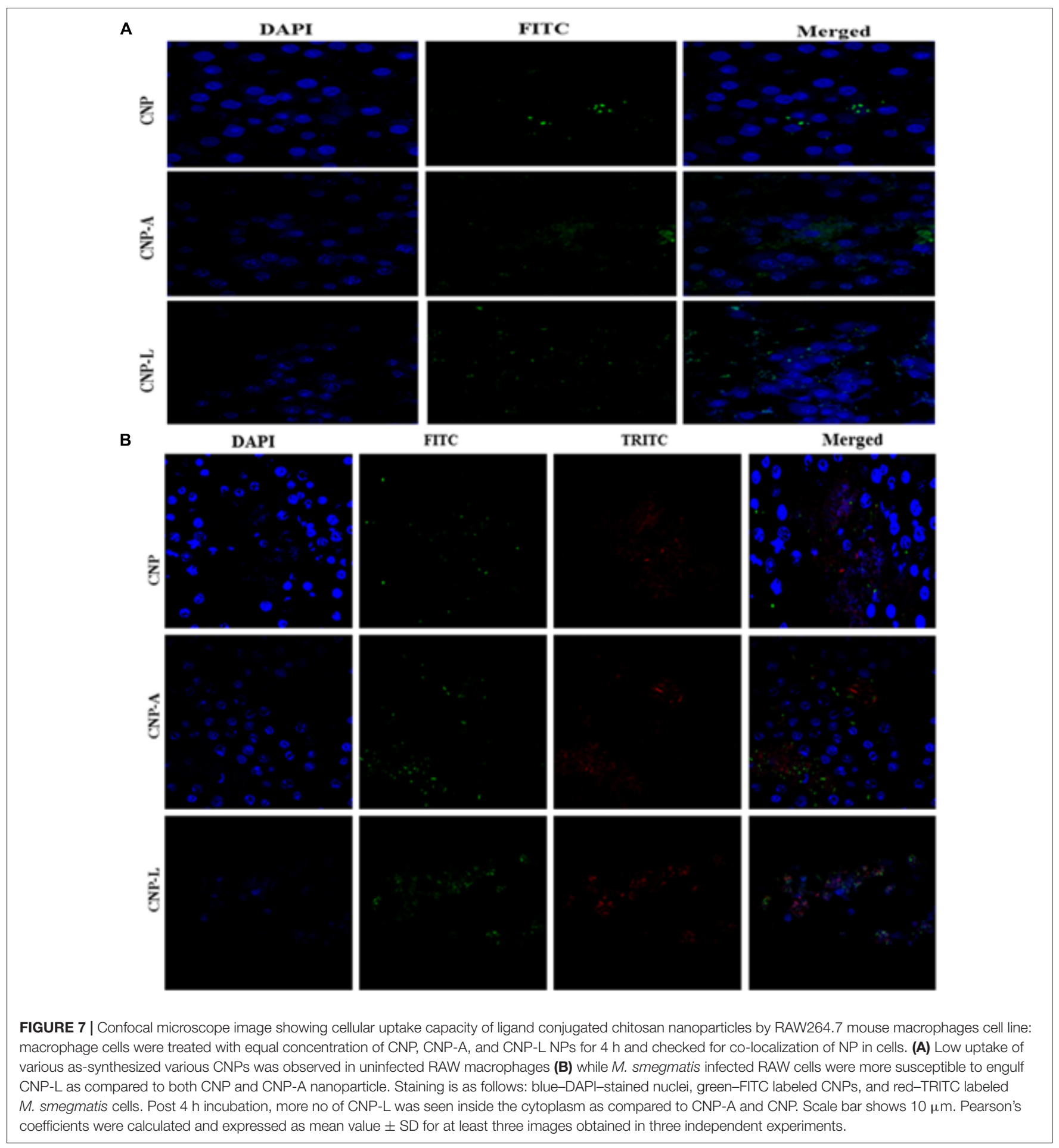

the presence of amine and hydroxyl groups. The as-synthesized CNPs, as determined by FTIR-spectra and TEM studies, were found to be spherical and remained stable for a longer duration. (Figures 1A,B).

The present study showed distinct differences in the susceptibility of $M$. smegmatis strain to various as-synthesized CNPs. CNP and CNP-L were found to be more effective in killing of $M$. smegmatis. In contrast, CNP-A was not significantly effective in killing of $M$. smegmatis due to unequal proportion of chitosan vs Acr-1 protein ratio as compared to other groups hence proving Acr-1 antigen has not manifested toxicity issue. The interaction of as-synthesized CNPs and M. smegmatis could be correlated to cationic chitosan and the negatively charged molecules present on bacterial cell wall (Raafat et al., 2008). 


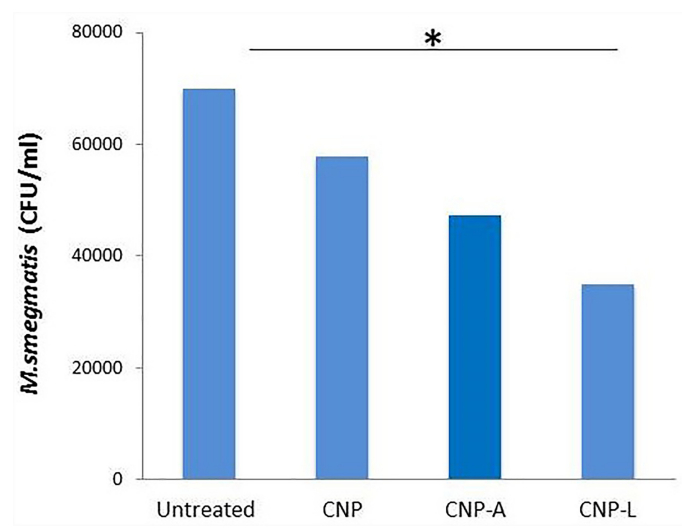

FIGURE 8 | Chitosan-based conjugated nanoparticles (CNPs) kill intracellular Mycobacterium smegmatis. RAW264.7 macrophage cells were incubated with various CNPs formulation for $24 \mathrm{~h}$ after $M$. smegmatis infection. Macrophages infected with bacteria alone were used as a control. The cells were lyzed after $24 \mathrm{~h}$ post-infected macrophages and intracellular bacterial survival was determined by determining colony-forming unit (CFU) assay. Experiments were performed in triplicate; results are shown as $\pm \mathrm{SD}$; $* P \leq 0.05$

In contrast, the mycobacteria cell wall is rich in lipids such as mycolic acids and thus limits the binding and permeability of drug molecules (Nikaido, 2003). To study the mechanism by which CNPs inactivate bacterial cells components, the effect on cell integrity and disturbance was evaluated by SEM (Figure 2). The data indicated that irreversible damage could be induced on mycobacterial cells after direct contact with CNPs and CNP-L treatment. The damage to the cell may be caused by interactions of CNP and CNP-L with free amino group- and sulfur-containing compounds (Sahariah and Masson, 2017). Both core chitosan and surface ligand moiety tend to have a high affinity for such molecules. The inhibitory effect could also be due to diffusion of CNPs through the channels present in the biofilms (Wilking et al., 2013). Taken together, the data indicate that chitosan-based CNPs not only exhibit potent anti-mycobactericidal activity but also impede the biofilm formation.

Mycobacterium has been reported to synthesize exopolysaccharides that protect it from the host cell offensives. The anti-biofilm activity could be correlated to inhibition of exopolysaccharide synthesis it has been shown that CNPs impair exopolysaccharide synthesis in $M$. smegmatis cells limiting the formation of biofilm (Hall-Stoodley and Stoodley, 2005). The inhibition of biofilm can also be linked to inhibition in iron uptake responsible for biofilm formation in Mycobacteria. This distinction could be because of the presence of abundant LPS, which leads to strong interaction with CNP, produced by M. smegmatis.
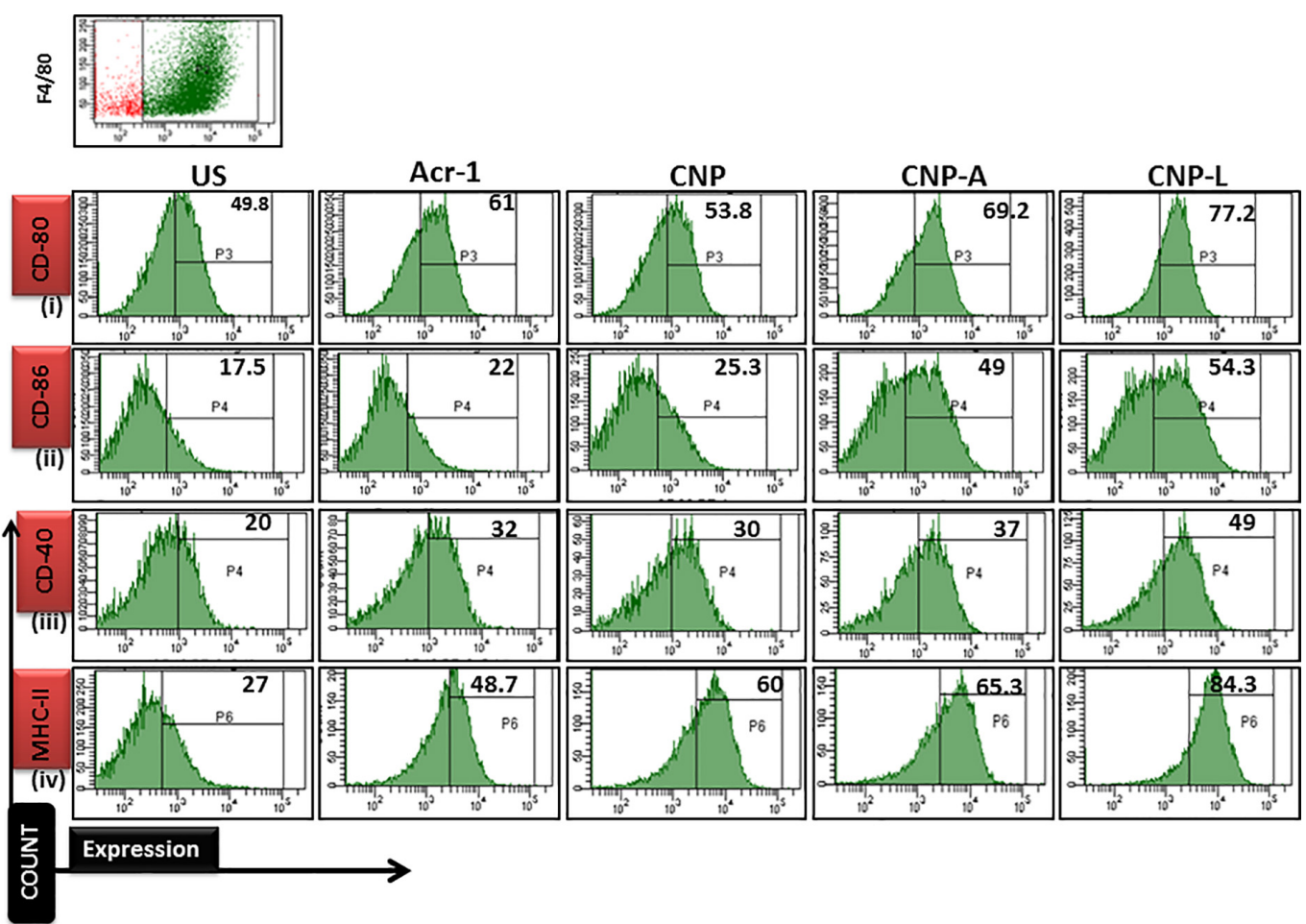

FIGURE 9 | Flow cytometry analysis of co-stimulatory molecule in M. smegmatis infected macrophages cell line: post 24 h treatment with all CNP, CNP-A, and CNP-L groups, infected macrophages cell were acquired and checked for costimulatory molecule expression by FACS analysis. (i-iv) showed that CNP-L group are more efficient to enhance upregulated expression of co-stimulatory molecule CD-40/80/86/MHC-II, expressed on M. smegmatis infected macrophage cell as compared to CNP and CNP-A group. 
The present study further demonstrated that CNPs treatment lead to generation of ROS production in M. smegmatis. The direct correlation between ROS generation and oxidative stress may lead to DNA damage, further suggest as an important route by which CNPs treatment causes DNA damage leading to inhibition or killing of M. smegmatis cells.

An important aspect for any molecule to be used as a therapeutic agent is that it should eliminate the target cells without affecting the viability of neighboring host cells. Many medically relevant polymeric nanoparticles such as chitosan biomaterial have been investigated for their cytotoxicity, but different researchers have reported varying effects for these nanoparticles on mammalian cells. The observed differences have been largely attributed to individual CNPs preparation methodologies and target cells.

The interaction of CNPs with mouse macrophages cell line RAW264.7 resulted in cell lysis at higher dose of chitosan treatment, while there was no harm to host macrophage cells up to dose of $100-300 \mu \mathrm{g} / \mathrm{ml}$. Interestingly, the same dose was found to have cytotoxic effect to $M$. smegmatis after $72 \mathrm{~h}$ of treatment. The formulation CNP-L that harbored a modifier at the particle surface has been shown to have a significant inhibitory effect against $M$. smegmatis strain. In contrast, CNP-A was found to have very less antimicrobial effect against $M$. smegmatis strain.

Macrophages can readily internalize foreign material ranging up to $10 \mu \mathrm{m}$ in size owing to their phagocytic function. Macrophages have been shown to be an ideal candidate for transporting antibacterial therapeutic molecule to various parts of the body. Since mycobacteria are an intracellular pathogen that halt the endo-lysosomal fusion and reside in the phagosomal compartments of macrophages, it is important to deliver the therapeutic molecules to the target sites that would otherwise be inaccessible due to the presence of physical barriers (Levitte et al., 2016).

We also observed active uptake of FITC-labeled CNPs by macrophages. CNPs uptake by the RAW264.7 cells was executed through C-type lectin receptors mediated endocytosis. The elevated intracellular killing of $M$. smegmatis could be because of the delivery of endocytosed CNP-L and CNPA to macrophages phagosome, where M. smegmatis resides. Alternatively, it could be because of the prolonged exposure $(24 \mathrm{~h})$ of CNPs treatment and release of Acr-1 from the CNP-A (Koppolu and Zaharoff, 2013). Treatment with CNPs upregulates the expression of co-stimulatory molecule such as CD80/86/40/MHC-II. The upregulation of co-stimulatory molecule is necessary for optimal activation of immune response that eventually results in elimination of pathogen.

\section{REFERENCES}

Adams, K. N., Takaki, K., Connolly, L. E., Wiedenhoft, H., Winglee, K., Humbert, O., et al. (2011). Drug tolerance in replicating mycobacteria mediated by a macrophage-induced efflux mechanism. Cell 145, 39-53. doi: 10.1016/j.cell. 2011.02.022

Agnihotri, S. A., Mallikarjuna, N. N., and Aminabhavi, T. M. (2004). Recent advances on chitosan-based micro-and nanoparticles in drug

\section{CONCLUSION}

The present study suggests that CNPs and CNP-L exhibit potent anti-mycobacterial activity against intracellularly residing M. smegmatis. CNP mediated mycobacterial cell inhibition may be attributed to both cell wall disruption as well as inactivation of thiol-containing proteins. Both CNPs and CNP-L exhibit potent anti-biofilm activity against $M$. smegmatis. The MTT assay and cell morphology analysis results showed that various CNPs groups exhibit no discernible cytotoxic effect on macrophages at the bactericidal concentration. In contrast, treatment with higher doses caused significant decrease in cell viability.

The cellular uptake study indicated that FITC-labeled CNP$\mathrm{L}$ are more efficiently and actively endocytosed by macrophages, which leads to intracellular killing of $M$. smegmatis. The present study concludes that CNP-A and CNP-L group elicit protective immune response against mycobacterial infection in host macrophages. Various CNPs nanoparticles developed in the present study provide a new insight that may help in designing both subunit vaccine as well as anti-tubercular drug delivery system to overcome the problem of drug resistance in Mycobacterial infections.

\section{AUTHOR CONTRIBUTIONS}

MO was responsible for the origin and design of the experiments. NM designed the experiments. MU and NM conducted the experimental procedures and data analysis. NM and OM wrote the manuscript. All authors approved the final version of the paper.

\section{ACKNOWLEDGMENTS}

The authors thank Prof. RHK the Coordinator of IBU, AMU, for providing Malvern Instrument for zeta potential and PDI experiment during this study. The authors are also thankful to Mr. Maaz and Mr. Shameem for support in TEM, SEM, and confocal microscopic studied. Finally, the authors are grateful to the OM for their fruitful discussions and suggestions.

\section{SUPPLEMENTARY MATERIAL}

The Supplementary Material for this article can be found online at: https://www.frontiersin.org/articles/10.3389/fmicb. 2018.02469/full\#supplementary-material

delivery. J. Control. Release 100, 5-28. doi: 10.1016/j.jconrel.2004. 08.010

Alex, S. M., Rekha, M. R., and Sharma, C. P. (2011). Spermine grafted galactosylated chitosan for improved nanoparticle mediated gene delivery. Int. J. Pharm. 410, 125-137. doi: 10.1016/j.ijpharm.2011. 02.067

Altaf, M., Miller, C. H., Bellows, D. S., and O’Toole, R. (2010). Evaluation of the Mycobacterium smegmatis and BCG models for the discovery of Mycobacterium 
tuberculosis inhibitors. Tuberculosis 90, 333-337. doi: 10.1016/j.tube.2010.09. 002

Amidi, M., Mastrobattista, E., Jiskoot, W., and Hennink, W. E. (2010). Chitosanbased delivery systems for protein therapeutics and antigens. Adv. Drug Deliv. Rev. 62, 59-82. doi: 10.1016/j.addr.2009.11.009

Anes, E., Peyron, P., Staali, L., Jordao, L., Gutierrez, M. G., Kress, H., et al. (2006). Dynamic life and death interactions between Mycobacterium smegmatis and J774 macrophages. Cell. Microbiol. 8, 939-960. doi: 10.1111/j.1462-5822.2005. 00675.x

Bonev, B., Hooper, J., and Parisot, J. (2008). Principles of assessing bacterial susceptibility to antibiotics using the agar diffusion method. J. Antimicrob. Chemother. 61, 1295-1301. doi: 10.1093/jac/dkn090

Boulos, L., Prevost, M., Barbeau, B., Coallier, J., and Desjardins, R. (1999). LIVE/DEAD BacLight: application of a new rapid staining method for direct enumeration of viable and total bacteria in drinking water. J. Microbiol. Methods 37, 77-86. doi: 10.1016/S0167-7012(99)00048-2

Chassaing, B., Rolhion, N., de Vallée, A., Salim, S. Y., Prorok-Hamon, M., Neut, C., et al. (2011). Crohn disease-associated adherent-invasive E. coli bacteria target mouse and human Peyer's patches via long polar fimbriae. J. Clin. Invest. 121, 966-975. doi: 10.1172/JCI44632

De Chastellier, C. (2009). The many niches and strategies used by pathogenic mycobacteria for survival within host macrophages. Immunobiology 214, 526542. doi: 10.1016/j.imbio.2008.12.005

Demotz, S., Grey, H. M., and Sette, A. (1990). The minimal number of class II MHC-antigen complexes needed for T cell activation. Science 249, 1028-1030. doi: $10.1126 /$ science. 2118680

Dong, H., Zhu, G., Tamada, K., and Chen, L. (1999). B7-H1, a third member of the B7 family, co-stimulates T-cell proliferation and interleukin-10 secretion. Nat. Med. 5, 1365-1369. doi: 10.1038/70932

Drickamer, K. (1992). Engineering galactose-binding activity into a C-type mannose-binding protein. Nature 360, 183-186. doi: 10.1038/ $360183 \mathrm{a} 0$

Dube, A., Lemmer, Y., Hayeshi, R., Balogun, M., Labuschagne, P., Swai, H., et al. (2013). State of the art and future directions in nanomedicine for tuberculosis. Expert Opin. Drug Deliv. 10, 1725-1734. doi: 10.1517/17425247.2014.846905

Eruslanov, E., and Kusmartsev, S. (2010). "Identification of ROS using oxidized DCFDA and flow-cytometry," in Advanced Protocols in Oxidative Stress II, ed. D. Armstrong (Totowa, NJ: Humana Press), 57-72. doi: 10.1007/978-1-60761411- 14

Espy, M. J., Uhl, J. R., Sloan, L. M., Buckwalter, S. P., Jones, M. F., Vetter, E. A., et al. (2006). Real-time PCR in clinical microbiology: applications for routine laboratory testing. Clin. Microbiol. Rev. 19, 165-256. doi: 10.1371/journal.pone.0192291

Fisichella, M., Dabboue, H., Bhattacharyya, S., Saboungi, M. L., Salvetat, J. P., Hevor, T., et al. (2009). Mesoporous silica nanoparticles enhance MTT formazan exocytosis in HeLa cells and astrocytes. Toxicol. Vitro 23, 697-703. doi: 10.1016/j.tiv.2009.02.007

Gan, Q., and Wang, T. (2007). Chitosan nanoparticle as protein delivery carriersystematic examination of fabrication conditions for efficient loading and release. Colloids Surf. B Biointerfaces 59, 24-34. doi: 10.1016/j.colsurfb.2007.04. 009

Hall-Stoodley, L., and Stoodley, P. (2005). Biofilm formation and dispersal and the transmission of human pathogens. Trends Microbiol. 13, 7-10. doi: 10.1016/j. tim.2004.11.004

Hashimoto, A., Suenaga, K., Gloter, A., Urita, K., and Iijima, S. (2004). Direct evidence for atomic defects in graphene layers. Nature 430, 870-873. doi: 10 . 1038/nature02817

He, C., Hu, Y., Yin, L., Tang, C., and Yin, C. (2010). Effects of particle size and surface charge on cellular uptake and biodistribution of polymeric nanoparticles. Biomaterials 31, 3657-3666. doi: 10.1016/j.biomaterials.2010.01. 065

Je, J. Y., and Kim, S. K. (2006). Chitosan derivatives killed bacteria by disrupting the outer and inner membrane. J. Agric. Food Chem. 54, 6629-6633. doi: 10.1016/j. ijfoodmicro.2004.01.022

Ko, J. A., Park, H. J., Hwang, S. J., Park, J. B., and Lee, J. S. (2002). Preparation and characterization of chitosan microparticles intended for controlled drug delivery. Int. J. Pharm. 249, 165-174. doi: 10.1016/S0378-5173(02) 00487-8
Kong, J., and Yu, S. (2007). Fourier transform infrared spectroscopic analysis of protein secondary structures. Acta Biochim. Biophys. Sin. 39, 549-559. doi: 10.1111/j.1745-7270.2007.00320.x

Koppolu, B., and Zaharoff, D. A. (2013). The effect of antigen encapsulation in chitosan particles on uptake, activation and presentation by antigen presenting cells. Biomaterials 34, 2359-2369. doi: 10.1016/j.biomaterials.2012.11.066

Kuo, J. H., Jan, M. S., Chang, C. H., Chiu, H. W., and Li, C. T. (2005). Cytotoxicity characterization of catanionic vesicles in RAW264.7 murine macrophage-like cells. Colloids Surf. B Biointerfaces 41, 189-196. doi: 10.1016/j.colsurfb.2004.12. 008

Levitte, S., Adams, K. N., Berg, R. D., Cosma, C. L., Urdahl, K. B., and Ramakrishnan, L. (2016). Mycobacterial acid tolerance enables phagolysosomal survival and establishment of tuberculous infection in vivo. Cell host microbe 20, 250-258. doi: 10.1016/j.chom.2016.07.007

Li, X., Kong, X., Shi, S., Zheng, X., Guo, G., Wei, Y., et al. (2008). Preparation of alginate coated chitosan microparticles for vaccine delivery. BMC Biotechnol. 8:89. doi: 10.1186/1472-6750-8-89

Lu, C. W., Hung, Y., Hsiao, J. K., Yao, M., Chung, T. H., Lin, Y. S., et al. (2007). Bifunctional magnetic silica nanoparticles for highly efficient human stem cell labeling. Nano Lett. 7, 149-154. doi: 10.1021/nl0624263

McGreal, E. P., Miller, J. L., and Gordon, S. (2005). Ligand recognition by antigenpresenting cell C-type lectin receptors. Curr. Opin. Immunol. 17, 18-24. doi: 10.1016/j.coi.2004.12.001

Meerak, J., Wanichwecharungruang, S. P., and Palaga, T. (2013). Enhancement of immune response to a DNA vaccine against Mycobacterium tuberculosis Ag85B by incorporation of an autophagy inducing system. Vaccine 31, 784-790. doi: 10.1016/j.vaccine.2012.11.075

Moghimi, S. M., Hunter, A. C., and Murray, J. C. (2005). Nanomedicine: current status and future prospects. FASEB J. 19, 311-330. doi: 10.5603/GP.a2017.0018

Nikaido, H. (2003). Molecular basis of bacterial outer membrane permeability revisited. Microbiol. Mol. Biol. Rev. 67, 593-656. doi: 10.1128/MMBR.67.4.593656.2003

No, H. K., Park, N. Y., Lee, S. H., and Meyers, S. P. (2002). Antibacterial activity of chitosans and chitosan oligomers with different molecular weights. Int. J. Food Microbiol. 74, 65-72. doi: 10.1016/S0168-1605(01)00717-6

Normington, K., Kohno, K., Kozutsumi, Y., Gething, M. J., and Sambrook, J. (1989). S. cerevisiae encodes an essential protein homologous in sequence and function to mammalian BiP. Cell 57, 1223-1236. doi: 10.1016/0092-8674(89) 90059-7

Prego, C., Paolicelli, P., Díaz, B., Vicente, S., Sánchez, A., González-Fernández, Á, et al. (2010). Chitosan-based nanoparticles for improving immunization against hepatitis B infection. Vaccine 28, 2607-2614. doi: 10.1016/j.vaccine.2010.01.011

Raafat, D., Von Bargen, K., Haas, A., and Sahl, H. G. (2008). Insights into the mode of action of chitosan as an antibacterial compound. Appl. Environ. Microbiol. 74, 3764-3773. doi: 10.1128/AEM.00453-08

Rabea, E. I., Badawy, M. E., Stevens, C. V., Smagghe, G., and Steurbaut, W. (2003). Chitosan as antimicrobial agent: applications and mode of action. Biomacromolecules 4, 1457-1465. doi: 10.1021/bm034130m

Rinaudo, M., Milas, M., and Le Dung, P. (1993). Characterization of chitosan. Influence of ionic strength and degree of acetylation on chain expansion. Int. J. Biol. Macromol. 15, 281-285. doi: 10.1016/0141-8130(93)90027-J

Sahariah, P., and Masson, M. (2017). Antimicrobial chitosan and chitosan derivatives: a review of the structure-activity relationship. Biomacromolecules 18, 3846-3868. doi: 10.1021/acs.biomac.7b01058

Stepanoviæ, S., Vukoviæ, D., Dakiæ, I., Saviæ, B., and Švabiæ-Vlahoviæ, M. (2000). A modified microtiter-plate test for quantification of staphylococcal biofilm formation. J. Microbiol. Methods 40, 175-179. doi: 10.1016/S0167-7012(00) 00122-6

Van Soolingen, D. (2001). Molecular epidemiology of tuberculosis and other mycobacterial infections: main methodologies and achievements. J. Intern. Med. 249, 1-26. doi: 10.1046/j.1365-2796.2001.00772.x

Wakamoto, Y., Dhar, N., Chait, R., Schneider, K., Signorino-Gelo, F., Leibler, S., et al. (2013). Dynamic persistence of antibiotic-stressed mycobacteria. Science 339, 91-95. doi: 10.1126/science. 1229858

Wang, T., Bai, J., Jiang, X., and Nienhaus, G. U. (2012). Cellular uptake of nanoparticles by membrane penetration: a study combining confocal microscopy with FTIR spectroelectrochemistry. ACS nano 6, 1251-1259. doi: $10.1021 / \mathrm{nn} 203892 \mathrm{~h}$ 
Weissleder, R., Kelly, K., Sun, E. Y., Shtatland, T., and Josephson, L. (2005). Cell-specific targeting of nanoparticles by multivalent attachment of small molecules. Nat. Biotechnol. 23, 1418-1423. doi: 10.1038/ nbt.1159

Wilking, J. N., Zaburdaev, V., De Volder, M., Losick, R., Brenner, M. P., and Weitz, D. A. (2013). Liquid transport facilitated by channels in Bacillus subtilis biofilms. Proc. Natl. Acad. Sci. U.S.A. 110, 848-852. doi: 10.1073/pnas. 1216376110

Wu, W., Wieckowski, S., Pastorin, G., Benincasa, M., Klumpp, C., Briand, J. P., et al. (2005). Targeted delivery of amphotericin B to cells by using functionalized carbon nanotubes. Angew. Chem. Int. Ed. Engl. 44, 6358-6362. doi: 10.1002/ ange. 200501613

Yang, S. C., Hsueh, P. R., Lai, H. C., Teng, L. J., Huang, L. M., Chen, J. M., et al. (2003). High prevalence of antimicrobial resistance in rapidly growing mycobacteria in Taiwan. Antimicrob. Agents Chemother. 47, 1958-1962. doi: 10.3201/eid.1502. 080837
Zambrano, M. M., and Kolter, R. (2005). Mycobacterial biofilms: a greasy way to hold it together. Cell 123, 762-764. doi: 10.1016/j.cell.2005.11.011

Conflict of Interest Statement: The authors declare that the research was conducted in the absence of any commercial or financial relationships that could be construed as a potential conflict of interest.

The handling Editor declared a shared affiliation, though no other collaboration with the authors.

Copyright (c) 2018 Mubin, Umar, Zubair and Owais. This is an open-access article distributed under the terms of the Creative Commons Attribution License (CC BY). The use, distribution or reproduction in other forums is permitted, provided the original author(s) and the copyright owner(s) are credited and that the original publication in this journal is cited, in accordance with accepted academic practice. No use, distribution or reproduction is permitted which does not comply with these terms. 